\title{
Social Media Behaviors and Experiences During the COVID-19 Pandemic: Associations With Anxiety, Depression, and Stress
}

\author{
J. Mitchell Vaterlaus, $\mathrm{PhD}$ \\ Montana State University, Bozeman, Montana, United States \\ (iD https://orcid.org/00oo-0001-7139-1457
}

Lori A. Spruance, $\mathrm{PhD}$

Brigham Young University, Provo, Utah, United States

(iD) http://orcid.org/0000-0003-0254-483X

Emily V. Patten, PhD

Brigham Young University, Provo, Utah, United States

(iD) http://orcid.org/0000-0003-0161-383X

Contact: j.vaterlaus@montana.edu

\section{Abstract}

The majority of research concerning public health crises and social media platforms has focused on analyzing the accuracy of information within social media posts. The current exploratory study explored social media users' specific social media behaviors and experiences during the early weeks of the COVID-19 pandemic and whether these behaviors and experiences related to anxiety, depression, and stress. Data were collected March 21-31, 2020 from adults in the United States $(N=564)$ through snowball sampling on social media sites and Prime Panels. Online surveys included questions regarding social media use during the pandemic and the Depression Anxiety and Stress Scales (DASS). Forward stepwise modeling procedures were used to build three models for anxiety, stress, and depression. Participants who actively engaged with COVID-19 social media content were more likely to experience higher anxiety. Those who had emotional experiences via social media and used social media to connect during the pandemic were susceptible to higher levels of stress and depression. The current study suggests that during the pandemic specific behaviors and experiences via social media were related to anxiety, stress, and depression. Thus, limiting time spent on social media during public health crises may protect the mental health of individuals.

Keywords: social media, social networking sites, mental health, COVID-19, pandemic

Date Submitted: March 23, 2021 | Date Published: September 27, 2021

\section{Recommended Citation}

Vaterlaus, J. M., Spruance, L. A., \& Patten, E. V. (2021). Social media behaviors and experiences during the COVID-19 pandemic: Associations with anxiety, depression, and stress. Journal of Social, Behavioral, and Health Sciences, 15(1), 217-230. https://doi.org/10.5590/JSBHS.2021.15.1.15

There was no funding to report for this research. We have no conflicts of interest to disclose. Correspondence regarding this article should be addressed to J. Mitchell Vaterlaus, Department of Health and Human Development, Montana State University, PO Box 173540 Bozeman, MT 59717, United States. Email: j.vaterlaus@montana.edu 


\section{Introduction}

The novel coronavirus (COVID-19) pandemic was declared a national emergency in the United States on March 13, 2020 (The White House, 2020). To slow the spread of the virus, various nonpharmaceutical public interventions were implemented and, by March 23, 2020, 43 states had state-wide (or partial state) stay-athome orders (Mervosh et al., 2020). This led to changes in household routines, including decreased access to supportive resources and increased social isolation (Brown et al., 2020). Emerging pandemic research indicated some adults experienced elevated symptoms of stress, anxiety, and depression during this time (Brown et al., 2020). Wiederhold (2020a) concluded that the COVID-19 pandemic was "impacting our collective mental health" and that social media can be both helpful and problematic in supporting human well-being during the pandemic (p. 275). Social media can facilitate interpersonal connection while people practice social distancing, but it can also be a place where anxiety and fear escalate with the dissemination of misinformation (Wiederhold, 2020a, 2020b).

Seventy-two percent of adults across demographic characteristics in the United States are active users of social media platforms (Pew Research Center, 2019). Adults report using YouTube (72\%), Facebook (69\%), Instagram (37\%), Pinterest (28\%), Snapchat (24\%), and Twitter (22\%; Perrin \& Anderson, 2019; Pew Research Center, 2019) and also report spending an average of 45 minutes daily using these platforms (The Nielson Company, 2019). Prepandemic reports indicate that adults used social media platforms for staying in touch with family and friends and for informational purposes (Shearer, 2018; Smith, 2011).

The convenience of social media makes it a primary source for the public to seek information during largescale disasters (Faustino et al., 2012). Much of the emerging research on social media use during public health crises (e.g., COVID-19, H1N1, H7N9, Zika Virus) has focused on the accuracy of information on social media platforms by analyzing specific posts (Chew \& Eysenbach, 2010; Pandey et al., 2010; Sharma et al., 2017). Most social media research specific to COVID-19 has been conducted with the Chinese microblogging social media application titled Weibo ( $\mathrm{Li}$, S. et al., 2020; Li, L. et al., 2020). Weibo posts during the pandemic have been categorized into various topic areas (e.g., advice, explanation of measures that have been taken, donation focused, providing support/asking for help, being critical, or refuting rumors; Li, L. et al., 2020) and, compared to posts prior to the pandemic, posts including negative emotions during the pandemic increased (Li, L. et al., 2020). Presently, it is unclear if specific behaviors on social media platforms during COVID-19 are related to stress, anxiety, and depression. Thus, the current study was designed to explore behaviors and experiences on social media and levels of stress, anxiety, and depression during the early weeks of the pandemic in the United States.

\section{Methods}

\section{Sample}

The sample included adults $(N=564)$ from 46 states in the United States (not represented: Alaska, Rhode Island, Vermont, and West Virginia). Most of the participants identified as female (61.52\%), White (80.82\%), and married (70.39\%). See Table 1 for sample characteristics. Participants reported using the following social media platforms: YouTube (85.59\%), Facebook (94.13\%), Instagram (70.94\%), Snapchat (41.10\%), Pinterest (54.19\%), and Twitter (40.14\%).

\section{Procedures}

Study procedures were approved by Montana State University's Institutional Review Board. Participants $(n=$ 600) were recruited through snowball sampling on social media sites and through Prime Panels (see https://www.cloudresearch.com/), which is an established way of recruiting diverse community samples (Chandler et al., 2019). Data collection occurred March 21-31, 2020, and the current study is part of a larger 
study focused on well-being during COVID-19 (see Vaterlaus et al., 2021). Participants completed online surveys created on Qualtrics (https://www.qualtrics.com). To be included in the current study participants needed to use at least one social media platform and 36 participants were not social media users.

Table 1. Demographic Characteristics of Sample

\begin{tabular}{|c|c|}
\hline Variable & $\begin{array}{c}\text { Total } \\
N=564, n(\%)\end{array}$ \\
\hline \multicolumn{2}{|l|}{ Age } \\
\hline 18-35 & $276(48.94)$ \\
\hline $36-55$ & $196(34.75)$ \\
\hline $56+$ & $92(16.13)$ \\
\hline \multicolumn{2}{|l|}{ Gender } \\
\hline Male & $216(38.37)$ \\
\hline Female & $347(61.63)$ \\
\hline \multicolumn{2}{|l|}{ Race } \\
\hline White & $455(80.82)$ \\
\hline All other races & $108(19.18)$ \\
\hline \multicolumn{2}{|l|}{ Sexual Orientation } \\
\hline Heterosexual & $539(95.91)$ \\
\hline Sexual minority & $23(4.09)$ \\
\hline \multicolumn{2}{|l|}{ Education } \\
\hline Less than HS degree or HS grad & $51(9.12)$ \\
\hline Some college of vocational school & $142(25.40)$ \\
\hline Bachelor's degree & $199(35.60)$ \\
\hline Graduate degree or professional degree & $167(29.87)$ \\
\hline \multicolumn{2}{|l|}{ Annual Income } \\
\hline Less than $\$ 20,000$ & $66(11.70)$ \\
\hline$\$ 20,000-\$ 39,999$ & $78(13.83)$ \\
\hline$\$ 40,000-\$ 59,999$ & $74(13.12)$ \\
\hline$\$ 60,000-\$ 74,999$ & $75(13 \cdot 30)$ \\
\hline$\$ 75,000-\$ 99,999$ & $91(16.13)$ \\
\hline$\$ 100,000-\$ 149,999$ & $104(18.44)$ \\
\hline$\$ 150,000$ or greater & $76(13.48)$ \\
\hline \multicolumn{2}{|l|}{ Marital } \\
\hline Single (divorced, widowed, single) & $167(29.61)$ \\
\hline Married/cohabitating & $397(70.39)$ \\
\hline \multicolumn{2}{|l|}{ Residence Location } \\
\hline Urban & $386(69.30)$ \\
\hline Suburban & $138(24.78)$ \\
\hline Rural & $33(5.92)$ \\
\hline \multicolumn{2}{|l|}{ Employment } \\
\hline Full-time & $276(49.02)$ \\
\hline Part-time & $104(18.47)$ \\
\hline Retired, stay-at-home parent, student, disabled & $152(27.00)$ \\
\hline Unemployed & $31(5.51)$ \\
\hline
\end{tabular}




\section{Measurement}

We asked participants for demographic information, COVID-19 information, social media use, COVID-19 related social media behaviors, mental health symptoms, and experience with loneliness. All items that were developed for this study were piloted with 20 adults prior to distributing the final survey.

\section{COVID-19 Information.}

Based on previous research on public health crises, items were developed that asked if participants had an underlying risk factor for COVID-19, their level of concern about COVID-19 (5-point Likert scale; not at all concerned to extremely concerned), and their current practice of social distancing (the five options ranged from I do not worry about staying in my residence and go a variety of places to I am on full lockdown and do not leave my residence).

\section{Social Media Use.}

Participants indicated whether they used each social media platform (i.e., YouTube, Facebook, Instagram, Pinterest, Snapchat, and Twitter) or not, and if they used the platform, they were asked to report how much time they spent daily with each platform during the last week (e.g., o minutes, 1-10 minutes, 11-30 minutes, 31-59 minutes, 1 hour, 2 hours, 3 hours, etc.). The midpoint of the category was taken to represent the number of minutes spent when response options included a range; all other categories used the corresponding number in minutes. Categories were summed into one variable encompassing the total number of hours participants indicated they spent on social media a day and then split into quartiles.

\section{COVID-19 Related Social Media Behaviors and Experiences.}

We asked participants to consider how often they had engaged in or experienced 13 different behaviors/experiences via social media (5-point Likert scale; never to every day) during the last week while experiencing the COVID-19 pandemic. A factor analysis was conducted between the 13 variables and three major factors were retained: Emotions and Personal Connections, Passive Engagement with COVID-19 Content, and Active Engagement with COVID-19 Content (see Table 2). Scales maintained the 5-point Likert categories.

\section{Mental health}

To understand participants' current anxiety, depression, and stress levels, the Depression Anxiety and Stress Scales (DASS-21; 21-item measure; 4-pt Likert scale) was completed (see Crawford \& Henry, 2003; Lovibond \& Lovibond, 1995). The scoring process resulted in three scores (anxiety, depression, and stress) by summing the scores, multiplying by two, and then categorizing the summed results by severity (normal, mild, moderate, severe, extremely severe; $\alpha=0.93)$.

\section{Loneliness}

To measure participants' levels of loneliness, we used the Three-Item Loneliness Scale (T-ILS; 3-point Likert scale; see Hughes et al., 2004; Matthews-Ewald \& Zullig, 2013). The scores were summed ( $\alpha=0.83)$, with higher scores indicating a higher degree of loneliness; scores were then categorized as being either lonely or not lonely.

\section{Analysis}

Data were analyzed in SAS, version 9.4 (SAS Institute, Cary, NC, USA). Univariate analyses were conducted for all variables to summarize mean, standard deviations, frequencies, and percentages. Three separate models were built between each outcome (anxiety, stress, and depression) and covariates with a $p$-value $<0.20$ were considered for the multivariable model. Each model was built using a forward stepwise modeling 
strategy and variables were retained if $p<0.05$. We considered both two-way interactions and main effects for each final model.

\section{Results}

We built three separate models for anxiety, depression, and stress. Table 1 and Table 3 include descriptive information about each of the outcome variables and covariates included in the models. Table 4 includes the model results. 
Table 2. Factor Loadings Related to Social Media Behaviors and Experiences During the Early Weeks of the COVID-19 Pandemic

\begin{tabular}{|c|c|c|c|}
\hline Items & $\begin{array}{c}\text { Emotions and } \\
\text { personal } \\
\text { connections } \\
(6 \text { items, } \alpha=.83)\end{array}$ & $\begin{array}{l}\text { Passive engagement } \\
\text { with COVID-19 } \\
\text { content } \\
\text { (4 items, } \alpha=.79 \text { ) }\end{array}$ & $\begin{array}{l}\text { Active engagement } \\
\text { with COVID-19 } \\
\text { content } \\
\text { (3 items, } \alpha=.81 \text { ) }\end{array}$ \\
\hline Reached out to someone you were concerned about & $\mathbf{0 . 3 7 5}$ & -0.230 & 0.030 \\
\hline Reached out to someone in order to feel close, connected, or together & 0.430 & -0.200 & -0.082 \\
\hline Looked for something humorous to make myself feel better & $\mathbf{0 . 1 7 5}$ & 0.1199 & -0.145 \\
\hline Felt more depressed or anxious using social media & 0.109 & 0.0783 & -0.060 \\
\hline $\begin{array}{l}\text { Used as a resource for activities/ideas during social distancing (e.g., } \\
\text { personal, activities for kids) }\end{array}$ & $\mathbf{0 . 2 5 7}$ & -0.076 & -0.020 \\
\hline Used a direct messaging feature to have conversations & 0.219 & -0.010 & -0.033 \\
\hline Read someone else's post about the Coronavirus/Pandemic & -0.226 & 0.431 & 0.0275 \\
\hline Read news updates about the Coronavirus/Pandemic & -0.138 & 0.363 & -0.021 \\
\hline Accessed social media out of boredom & -0.085 & 0.375 & -0.136 \\
\hline $\begin{array}{l}\text { Used as a resource for information in your own community (e.g., closures, } \\
\text { access supplies) }\end{array}$ & 0.076 & 0.129 & -0.011 \\
\hline Made personal post about the Coronavirus/Pandemic & -0.030 & -0.152 & 0.449 \\
\hline Liked a post about the Coronavirus/Pandemic & -0.173 & 0.127 & 0.362 \\
\hline Commented on a post about the Coronavirus/Pandemic & -0.054 & -0.093 & 0.450 \\
\hline
\end{tabular}

Note. Participants were asked to report during the last week, while experiencing the COVID-19 pandemic, how often they engaged in specific social media behaviors or experiences ( $n=13$ items). All scales had 5-point Likert response choices: Never, Almost never, Occasionally, Almost Every Day, and Everyday 
Table 3. Descriptive Statistics of Mental Health, COVID-19, and Social Media Variables

\begin{tabular}{|c|c|}
\hline Variable & $\begin{array}{l}\text { Total } \\
N=564, n(\%)\end{array}$ \\
\hline \multicolumn{2}{|l|}{ Mental Health Variables } \\
\hline \multicolumn{2}{|l|}{ Stress } \\
\hline Normal & $415(73.58)$ \\
\hline Mild & $65(11.52)$ \\
\hline Moderate & $41(7.27)$ \\
\hline Severe & $35(6.21)$ \\
\hline Extremely Severe & $8(1.42)$ \\
\hline \multicolumn{2}{|l|}{ Anxiety } \\
\hline Normal & $410(72.70)$ \\
\hline Mild & $38(6.74)$ \\
\hline Moderate & $60(10.64)$ \\
\hline Severe & $22(3.90)$ \\
\hline Extremely Severe & $34(6.03)$ \\
\hline \multicolumn{2}{|l|}{ Depression } \\
\hline Normal & $375(66.49)$ \\
\hline Mild & $71(12.59)$ \\
\hline Moderate & $78(13.83)$ \\
\hline Severe & $22(3.90)$ \\
\hline Extremely Severe & $18(3.19)$ \\
\hline \multicolumn{2}{|l|}{ Loneliness } \\
\hline Not Lonely & $391(69.33)$ \\
\hline Lonely & $173(30.67)$ \\
\hline \multicolumn{2}{|l|}{ COVID-19 Variables } \\
\hline \multicolumn{2}{|l|}{ Social Distancing } \\
\hline I do not worry about staying in my residence and go a variety of places & $16(2.84)$ \\
\hline I stay in my residence as much as possible, but have to go to work & $86(15.25)$ \\
\hline $\begin{array}{l}\text { I leave my residence for essential trips (e.g., groceries, medical, caregiving) } \\
\text { and exercise }\end{array}$ & $410(72.70)$ \\
\hline I am on full lockdown and do not leave my residence & $52(9.22)$ \\
\hline \multicolumn{2}{|l|}{ Concern for COVID-19 } \\
\hline Not concerned & $14(2.49)$ \\
\hline Slightly concerned & $82(14.56)$ \\
\hline Somewhat concerned & $119(21.14)$ \\
\hline Moderately concerned & $177(31.44)$ \\
\hline Extremely concerned & $171(30.37)$ \\
\hline \multicolumn{2}{|l|}{ Underlying risk factor for COVID-19 } \\
\hline No & $470(83.33)$ \\
\hline Yes & $94(16.67)$ \\
\hline
\end{tabular}




\begin{tabular}{|c|c|}
\hline Variable & $\begin{array}{l}\text { Total } \\
N=564, n(\%)\end{array}$ \\
\hline \multicolumn{2}{|l|}{ Social Media Variables } \\
\hline \multicolumn{2}{|l|}{ Emotions and Personal Connections Scale } \\
\hline Never & $51(9.04)$ \\
\hline Almost never & $135(23.94)$ \\
\hline Occasionally & $219(38.83)$ \\
\hline Almost every day & $149(26.42)$ \\
\hline Everyday & $10(1.77)$ \\
\hline \multicolumn{2}{|c|}{ Passive Engagement with COVID-19 Content Scale } \\
\hline Never & $25(4.43)$ \\
\hline Almost never & $56(9.93)$ \\
\hline Occasionally & $157(27.84)$ \\
\hline Almost every day & $255(45 \cdot 21)$ \\
\hline Everyday & $71(12.59)$ \\
\hline \multicolumn{2}{|c|}{ Active Engagement with COVID-19 Content Scale } \\
\hline Never & $205(36.35)$ \\
\hline Almost never & $155(27.48)$ \\
\hline Occasionally & $142(25.18)$ \\
\hline Almost every day & $53(9.40)$ \\
\hline Everyday & $9(1.60)$ \\
\hline \multicolumn{2}{|c|}{ Average Total Time Spent on Social Media (across platforms) per day } \\
\hline 4 hours or less per day & $163(28.90)$ \\
\hline More than 4 hours -8 hours a day & $127(22.52)$ \\
\hline More than 8 hours -12.5 hours a day & $139(24.65)$ \\
\hline More than 12.5 hours a day & $135(23.94)$ \\
\hline
\end{tabular}


Table 4. Social Media Behaviors and Experiences During COVID-19: Adjusted Effects Between Anxiety, Stress, and Depression and Covariates

\begin{tabular}{|c|c|c|c|}
\hline Variable & $\begin{array}{c}\text { Anxiety Outcome } \\
\text { Odds Ratio } \\
\text { (Confidence Interval) }\end{array}$ & $\begin{array}{c}\text { Stress Outcome } \\
\text { Odds Ratio } \\
\text { (Confidence Interval) }\end{array}$ & $\begin{array}{l}\text { Depression Outcome } \\
\text { Odds Ratio } \\
\text { (Confidence Interval) }\end{array}$ \\
\hline \multicolumn{4}{|l|}{$\begin{array}{l}\text { Emotions and Personal Connections via } \\
\text { Social Media }\end{array}$} \\
\hline Never & --- & Ref. & Ref. \\
\hline Almost never & & $0.848(0.329,2.185)$ & $1.036(0.444,2.417)$ \\
\hline Occasionally & & $1.363(0.567,3.275)$ & $2.059(0.916,4.632)$ \\
\hline Almost every day & & $2.086(0.849,5.126)$ & $2.256(0.967,5.263)$ \\
\hline Everyday & & $4.737(1.140,19.675)$ & $4.622(1.123,19.024)$ \\
\hline \multicolumn{4}{|l|}{ Loneliness } \\
\hline Not Lonely & Ref. & Ref. & Ref. \\
\hline Lonely & $2.140(1.412,3.243)$ & $2.097(1.402,3.138)$ & $4.131(2.815,6.061)$ \\
\hline \multicolumn{4}{|l|}{ Age } \\
\hline 18-35 & Ref. & Ref. & Ref. \\
\hline $36-55$ & $0.712(0.456,1.111)$ & $0.736(0.481,1.122)$ & $0.513(0.341,0.773)$ \\
\hline $56+$ & $0.376(0.178,0.795)$ & $0.229(0.146,0.611)$ & $0.308(0.164,0.577)$ \\
\hline \multicolumn{4}{|l|}{ Social Distancing } \\
\hline $\begin{array}{l}\text { I am on full lockdown and do not leave my } \\
\text { residence }\end{array}$ & --- & --- & Ref. \\
\hline I leave my residence for essential trips & & & $0.359(0.202,0.913)$ \\
\hline $\begin{array}{l}\text { I stay in my residence as much as possible, but } \\
\text { have to go to work }\end{array}$ & & & $0.446(0.218,0.913)$ \\
\hline $\begin{array}{l}\text { I do not worry about staying in my residence } \\
\text { and go a variety of places }\end{array}$ & & & $0.314(0.090,1.094)$ \\
\hline \multicolumn{4}{|l|}{ Sexual Orientation } \\
\hline Heterosexual & Ref. & --- & Ref. \\
\hline Sexual minority & $3.407(1.483,7.824)$ & & $2.624(1.122,6.141)$ \\
\hline
\end{tabular}




\begin{tabular}{|c|c|c|c|}
\hline Variable & $\begin{array}{c}\text { Anxiety Outcome } \\
\text { Odds Ratio } \\
\text { (Confidence Interval) }\end{array}$ & $\begin{array}{c}\text { Stress Outcome } \\
\text { Odds Ratio } \\
\text { (Confidence Interval) }\end{array}$ & $\begin{array}{l}\text { Depression Outcome } \\
\text { Odds Ratio } \\
\text { (Confidence Interval) }\end{array}$ \\
\hline \multicolumn{4}{|l|}{ Concern for COVID-19 } \\
\hline Extremely concerned & Ref. & Ref. & \\
\hline Moderately concerned & $0.591(0.368,0.950)$ & $0.598(0.378,0.946)$ & --- \\
\hline Somewhat concerned & $0.220(0.113,0.432)$ & $0.257(0.135,0.490)$ & \\
\hline Slightly concerned & $0.174(0.078,0.390)$ & $0.414(0.212,0.810)$ & \\
\hline Not concerned & $0.456(0.116,1.793)$ & $0.500(0.124,0.810)$ & \\
\hline \multicolumn{4}{|l|}{ Gender } \\
\hline Male & --- & --- & Ref. \\
\hline Female & & & $0.478(0.315, .0726)$ \\
\hline Race/Ethnicity & & --- & \\
\hline White & --- & & Ref. \\
\hline All other race/ethnicities & & & $0.505(0.297,0.857)$ \\
\hline \multicolumn{4}{|c|}{$\begin{array}{l}\text { Active Engagement with COVID-19 Content } \\
\text { by Gender }\end{array}$} \\
\hline \multicolumn{4}{|c|}{ Female } \\
\hline Never & Ref. & & \\
\hline Almost never & $1.252(0.619,2.533)$ & & \\
\hline Occasionally & $1.982(1.010,3.888)$ & --- & --- \\
\hline Almost every day & $1.343(0.458,3.715)$ & & \\
\hline Everyday & $0.488(0.049,4.821)$ & & \\
\hline \multicolumn{4}{|l|}{ Male } \\
\hline Never & Ref. & & \\
\hline Almost never & $1.194(0.454,3.1420)$ & & \\
\hline Occasionally & $2.808(1.186,6.647)$ & & \\
\hline Almost every day & $10.715(3.896,29.470)$ & & \\
\hline Everyday & $3.968(0.284,55.475)$ & & \\
\hline
\end{tabular}




\section{Anxiety.}

Together, concern for COVID-19, sexual orientation, loneliness, age, and an interaction between age and active engagement with COVID-19 content on social media were significantly related to higher anxiety (see Table 4). The relationship between active engagement with social media content about COVID-19 and higher anxiety was dependent on gender. For example, both males and females who actively engaged with COVID-19 social media content occasionally were about two times more likely to experience higher levels of anxiety compared to those who never actively engaged with COVID-19 social media content, but males who actively engaged with COVID-19 content on social media almost every day were more than 10 times more likely to experience higher rates of anxiety compared to males who never actively engaged with COVID-19 social media content. There was not a significant relationship in anxiety levels between female participants who never actively engaged with COVID-19 content on social media and those who did almost every day.

\section{Stress.}

Concern for COVID-19, loneliness, age, and those who had emotional experiences and made personal connections on social media during the pandemic were together associated with higher levels of stress (see Table 4). Participants who had emotional experiences via social media and used it for connection every day were almost five times as likely to have higher levels of stress compared to those who did not experience social media this way during the early weeks of the pandemic.

\section{Depression.}

Together, loneliness, age, sexual orientation, gender, ethnicity, having emotional experiences, and making personal connections on social media during the early weeks of the pandemic were associated with higher levels of depression (see Table 4). Participants who had emotional experiences via social media and used it for connection every day were almost five times as likely to have higher levels of depression compared to those who did not experience social media this way during the early weeks of the pandemic.

\section{Discussion}

The current study explored the potential relationship between social media experiences and behaviors and anxiety, depression, and stress during the early weeks of the COVID-19 pandemic. There have been mixed results regarding the relationship between mental health and social media during nonpandemic times (Pantic, 2014). Vannucci et al. (2017) identified that greater social media use was related to higher levels of anxiety. In the present study, those who occasionally actively engaged with COVID-19 content (liked, commented, or created a post) were more likely to experience higher levels of anxiety than those who never engaged in COVID-19-related social media behaviors. Further, in terms of experiences with elevated stress and depression, participants who reported experiencing emotional reactions via social media or using it to connect with people during the pandemic were more susceptible to higher levels of stress and depression.

The cross-sectional design does not allow for the determining directionality of these findings. Previous research with people diagnosed with serious mental health illnesses and their use of social media found that social media use was not related to psychiatric symptoms, which may imply that social media does not make symptoms worse (Brusilovskiy et al., 2016). Another recent study identified that young adults who had high levels of anxiety and depression were more likely to consider using social media for support (over parents and mental health professionals), but they also reported that social media could be stress inducing (Drouin et al., 2018). As such, emotional experiences and connecting personally through social media during pandemics may elevate symptoms of stress and depression and also provide a venue to receive social support. Longitudinal research is needed. 


\section{Limitations and Conclusions}

There are limitations to this study. While appropriate for an exploratory study, the study relied on a nonprobability sampling procedure and the sample was homogenous in terms of race, which limits the generalizability of the results. Interestingly, males and underrepresented racial groups were less likely to have higher depression than women and those identifying as White. This is contradictory to most research on depression and emerging research on depression during the pandemic (Ettman et al., 2020). This contradiction may be explained by sampling procedure limitations, which led to recruitment of people who were highly educated, mostly employed, and who had higher incomes. Pandemic research on depression highlights that those with lower economic resources and stressors were susceptible to higher levels of depression (Ettman et al., 2020). Future replication studies using random sampling procedures and specific studies related to the experiences of social media use by individuals with low resources during public health crises are warranted. However, adults use social media across demographic characteristics (Perrin \& Anderson, 2019; Pew Research Center, 2019), and people of all resource levels have experienced the pandemic, which means the current results should not be discounted but considered in the context of the limitations.

In terms of study strengths, the study did move social media and public health crisis research beyond the examination of existing posts for accuracy/inaccuracy of health-based information and focused on user experiences. The current study captured the specific experiences and behaviors on social media as reported by people who were experiencing the early weeks of the COVID-19 pandemic. The current study suggests that during the early weeks of the pandemic, specific behaviors and experiences via social media were related to anxiety, stress, and depression. Early in the pandemic, some scholars recommended limiting time on social media as a method of preventing mental health declines (Kar et al., 2020). Results from the current study provide some preliminary support for this recommendation, and limiting time spent on social media during public health crises may be a way to protect mental health. 


\section{References}

Brown, S. M., Doom, J. R., Lechuga-Peña, S., Watamura, S. E., \& Koppels, T. (2020). Stress and parenting during the global COVID-19 pandemic. Child Abuse and Neglect, 11O(Pt 2), 1-14. https://doi.org/10.1016/j.chiabu.2020.104699

Brusilovskiy, E., Townley, G., Snethen, G., \& Salzer, M. S. (2016). Social media use, community participation and psychological well-being among individuals with serious mental illnesses. Computers in Human Behavior, 65, 232-240. https://doi.org/10.1016/j.chb.2016.08.036

Chandler, J., Rosenzweig, C., Moss, A. J., Robinson, J., \& Litman, L. (2019). Online panels in social science research: Expanding sampling methods beyond Mechanical Turk. Behavior Research Methods, 51, 2022-2038. https://doi.org/10.3758/s13428-019-01273-7

Chew, C., \& Eysenbach, G. (2010). Pandemics in the age of Twitter: Content analysis of Tweets during the 2009 H1N1 outbreak. PloS One, 5(11), e14118. https://doi.org/10.1371/journal.pone.0014118

Crawford, J. R., \& Henry, J. D. (2003). The Depression Anxiety Stress Scales (DASS): Normative data and latent structure in a large non-clinical sample. British Journal of Clinical Psychology, 42(Pt 2), 111131.

Drouin, M., Reining, L., Flanagan, M., Carpenter, M., \& Toscos, T. (2018). College students in distress: Can social media be a source of social support? College Student Journal, 52, 494-504.

Ettman, C. K., Abdalla, S. M., Cohen, G. H., Sampson, L., Vivier, P. M., \& Galea, S. (2020). Prevalence of depression symptoms in U.S. adults before and during the COVID-19 pandemic. JAMA Network Open, 3(9), e2019686-e2019686. https://doi.org/10.1001/jamanetworkopen.2020.19686

Faustino, J. D., Liu, B. F., \& Jin, Y. (2012). Social media use during disasters: A review of the knowledge base and gaps. U.S. Department of Homeland Security.

Hughes, M. E., Waite, L. J., Hawkley, L. C., \& Cacioppo, J. T. (2004). A short scale for measuring loneliness in large surveys: Results from two population-based studies. Research on Aging, 26(6), 655-672. https://doi.org/10.1177/0164027504268574

Kar, S. K., Yasir Arafat, S. M., Kabir, R., Sharma, P., \& Saxena, S. K. (2020). Coping with mental health challenges during COVID-19. In S. Saxena (Ed.), Coronavirus Disease 2019 (COVID-19): Epidemiology, pathogenesis, diagnosis, and therapeutics (pp. 199-213). Springer.

Li, L., Zhang, Q., Wang, X., Zhang, J., Wang, T., Gao, T. L., Duan, W., Tsoi, K. K., \& Wang, F. Y. (2020). Characterizing the propagation of situational information in social media during COVID-19 epidemic: A case study on Weibo. IEEE Transactions on Computational Social Systems, 7(2), 556-562. https://doi.org/10.1109/TCSS.2020.2980007

Li, S., Wang, Y., Xue, J., Zhao, N., \& Zhu, T. (2020). The impact of COVID-19 epidemic declaration on psychological consequences: A study on active Weibo users. International Journal of Environmental Research and Public Health, 17(6), 2032. https://doi.org/10.3390/ijerph17062032

Lovibond, S. H., \& Lovibond, P. F. (1995). Manual for the Depression Anxiety \& Stress Scales. Psychology Foundation.

Matthews-Ewald, M. R., \& Zullig, K. J. (2013). Evaluating the performance of a short loneliness scale among college students. Journal of College Student Development, 54(1), 105-109.

https://doi.org/10.1353/csd.2013.0003

Mervosh, S., Lu, D., \& Swales, V. (2020, April 20). See which states and cities have told residents to stay at home. The New York Times. https://www.nytimes.com/interactive/2020/us/coronavirus-stay-athome-order.html 
Pandey, A., Patni, N., Singh, M., Sood, A., \& Singh, G. (2010). YouTube as a source of information on the H1N1 influenza pandemic. American Journal of Preventive Medicine, 38(3), e1-e3. https://doi.org/10.1016/j.amepre.2009.11.007

Pantic, I. (2014). Online social networking and mental health. Cyberpsychology, Behavior, and Social Networking, 17(10), 652-657. https://doi.org/10.1089/cyber.2014.0070

Perrin, A., \& Anderson, M. (2019). Share of U.S. adults using social media, including Facebook, is mostly unchanged since 2018. Pew Research Center. https://www.pewresearch.org/facttank/2019/o4/10/share-of-u-s-adults-using-social-media-including-facebook-is-mostly-unchangedsince-2018/

Pew Research Center. (2019). Social media fact sheet. https://www.pewresearch.org/internet/factsheet/social-media/

Sharma, M., Yadav, K., Yadav, N., \& Ferdinand, K. C. (2017). Zika virus pandemic-analysis of Facebook as a social media health information platform. American Journal of Infection Control, 45(3), 301-302. https://doi.org/10.1016/j.ajic.2016.08.022

Shearer, E. (2018). Social media outpaces print newspapers in the U.S. as a news source. Pew Research Center. https://www.pewresearch.org/fact-tank/2018/12/10/social-media-outpaces-printnewspapers-in-the-u-s-as-a-news-source/

Smith, A. (2011). Why Americans use social media. Pew Research Center. https://www.pewresearch.org/internet/2011/11/15/why-americans-use-social-media/

The Nielsen Company. (2019). The Nielsen total audience report Q3 2018. https://www.nielsen.com/wpcontent/uploads/sites/3/2019/04/q3-2018-total-audience-report.pdf

The White House. (2020, March 13). Proclamation on declaring a national emergency concerning the Novel Coronavirus Disease (COVID-19) outbreak [Proclamation]. https://trumpwhitehouse.archives.gov/presidential-actions/proclamation-declaring-nationalemergency-concerning-novel-coronavirus-disease-covid-19-outbreak/

Vannucci, A., Flannery, K. M., \& Ohannessian, C. M. (2017). Social media use and anxiety in emerging adults. Journal of Affective Disorders, 207, 163-166. https://doi.org/10.1016/j.jad.2016.08.040

Vaterlaus, J. M., Spruance, L. A., \& Patten, E. V. (2021). COVID-19 pandemic and social distancing in the United States: A mixed-methods study on lived experiences and well-being. The Social Science Journal. https://doi.org/10.1080/03623319.2020.1852856

Wiederhold, B. K. (2020a). Social media use during social distancing. Cyberpsychology, Behavior, and Social Networking, 23(5), 275-276. https://doi.org/10.1089/cyber.2020.29181.bkw

Wiederhold, B. K. (2020b). Using social media to our advantage: Alleviating anxiety during a pandemic. Cyberpsychology, Behavior, and Social Networking, 23(4), 197-198. https://doi.org/10.1089/cyber.2020.29180.bkw

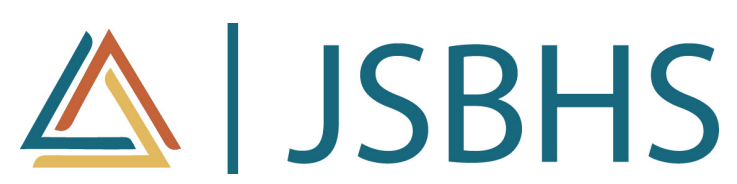

The Journal of Social, Behavioral, and Health Sciences ( $J S B H S$ ), co-sponsored by the College of Health Sciences and the College of Social and Behavioral Sciences at Walden University, is a peer-reviewed, online, interdisciplinary journal focusing on theoretically-based research that addresses contemporary national and international issues. JSBHS articles include peer-reviewed research reports, brief reports, comprehensive literature reviews, book reviews, and student research. 